\title{
STRETCH AND ACTIVATION OF THE HUMAN BIARTICULAR HAMSTRINGS ACROSS A RANGE OF RUNNING SPEEDS
}

\author{
Anthony G. Schache ${ }^{1}$, Tim W. Dorn ${ }^{1}$ Tim V. Wrigley ${ }^{2}$, Nicholas A. T. Brown ${ }^{3}$, \\ and Marcus G. Pandy ${ }^{1}$
}

\footnotetext{
${ }^{1}$ Department of Mechanical Engineering, University of Melbourne, Victoria 3010 Australia

${ }^{2}$ Centre for Health Exercise and Sports Medicine, University of Melbourne, Victoria 3010

Australia

${ }^{3}$ Department of Biomechanics and Performance Analysis, Australian Institute of Sport, Belconnen ACT 2616 Australia
}

Submitted to: European Journal of Applied Physiology.

Contact information for corresponding author:

Dr Anthony G. Schache

Department of Mechanical Engineering, University of Melbourne, Victoria 3010 Australia

Telephone: +61 (03) 8344-6748; Fax: +61 (03) 8344-4290; Email: anthonys@ unimelb.edu.au 


\section{Abstract}

Purpose: The human biarticular hamstrings (semimembranosus (SM), semitendinosus (ST) and biceps femoris long head $\left.\left(\mathrm{BF}^{\mathrm{LH}}\right)\right)$ have an important role in running. This study determined how hamstrings neuro-mechanical behaviour changed with faster running, and whether differences existed between $\mathrm{SM}, \mathrm{ST}$ and $\mathrm{BF}^{\mathrm{LH}}$.

Methods: Whole-body kinematics and hamstrings electromyographic (EMG) activity were measured from seven participants running at four discrete speeds (range: $3.4 \pm 0.1 \mathrm{~m} / \mathrm{s}$ to $9.0 \pm 0.7$ $\mathrm{m} / \mathrm{s})$. Kinematic data were combined with a three-dimensional musculoskeletal model to calculate muscle-tendon unit (MTU) stretch and velocity. Activation duration and magnitude were determined from EMG data.

Results: With faster running, MTU stretch and velocity patterns remained similar but maxima and minima significantly increased. The hamstrings were activated from foot-strike until terminal stance or early swing, and then again from mid-swing until foot-strike. Activation duration was similar with faster running, whereas activation magnitude significantly increased. Hamstrings activation almost always ended before minimum MTU stretch, and it always started before maximum MTU stretch. Comparing the hamstrings, maximum MTU stretch was largest for $\mathrm{BF}^{\mathrm{LH}}$ and smallest for ST irrespective of running speed, while the opposite was true for peakto-peak MTU stretch. Furthermore, peak MTU shortening velocity was largest for ST and smallest for $\mathrm{BF}^{\mathrm{LH}}$ at all running speeds. Finally, for the two fastest running speeds, the amount of MTU stretch that occurred during terminal swing after activation had started was less for BF ${ }^{\mathrm{LH}}$ compared to SM and ST. 
Conclusion: Differences were evident in biarticular hamstrings neuro-mechanical behaviour during running. Such findings have implications for hamstrings function and injury.

Keywords: Eccentric contraction; Biceps femoris long head; Muscle strain-type injury; Sprinting 


\section{Introduction}

The hamstrings are thought to play an important role in human locomotion, especially as speed approaches maximal limits. It has been proposed that these muscles function to decelerate the leg during the terminal swing phase of the stride cycle in order to move the foot underneath the body's centre of mass in preparation for foot-strike, after which they aid with hip extension and knee-joint stability throughout stance (Schache et al. 2012). The hamstrings complex is comprised of three muscles: semimembranosus (SM), semitendinosus (ST) and biceps femoris $(\mathrm{BF})$, which has both a short head $\left(\mathrm{BF}^{\mathrm{SH}}\right)$ and a long head $\left(\mathrm{BF}^{\mathrm{LH}}\right) . \mathrm{BF}^{\mathrm{SH}}$ arises from the femur and shares a common distal tendon with $\mathrm{BF}^{\mathrm{LH}}$, making it a uniarticular muscle that spans the knee joint only. In contrast, $\mathrm{SM}, \mathrm{ST}$ and $\mathrm{BF}^{\mathrm{LH}}$ all arise from the ischial tuberosity on the pelvis, hence are biarticular muscles that span the hip and knee joints. In terms of their dominant action (i.e., hip extension and knee flexion), SM, ST and $\mathrm{BF}^{\mathrm{LH}}$ represent a group of functionally synergistic muscles.

When comparing architectural and geometrical properties for SM, ST and $\mathrm{BF}^{\mathrm{LH}}$ there are a number of distinguishing characteristics. For example, ST is a parallel-fibred (fusiform) muscle, whereas $\mathrm{SM}$ and $\mathrm{BF}^{\mathrm{LH}}$ have a mixed unipennate and bipennate arrangement (Kumazaki et al. 2012; Woodley and Mercer 2005). There are also well known differences in muscle-fibre length and physiological cross-sectional area (PCSA) (Kellis et al. 2012; Ward et al. 2009). Of the three muscles, ST has the longest muscle-fibre lengths and the smallest PCSA, whereas SM has the shortest muscle-fibre lengths and the largest PCSA. BF ${ }^{\mathrm{LH}}$ has muscle-fibre lengths that are 
longer than SM but shorter than ST and a PCSA that is larger than ST but smaller than SM. Finally, there are differences in the lines-of-action and moment-arm magnitudes between SM, ST and $\mathrm{BF}^{\mathrm{LH}}$, especially about the knee joint (Arnold et al. 2000; Buford et al. 1997; Herzog and Read 1993). Given such distinguishing characteristics, we were interested in determining whether differences also existed in the neuro-mechanical behaviour of the biarticular hamstrings during a functional task that specifically challenges these muscles, such as fast running.

Evidence is available indicating that $\mathrm{SM}, \mathrm{ST}$ and $\mathrm{BF}^{\mathrm{LH}}$ display differences in certain biomechanical parameters with fast running. Maximum MTU stretch (i.e., maximum change in MTU length relative to that assumed in an upright stance posture) has been found to be greater for $\mathrm{BF}^{\mathrm{LH}}$ compared to SM and ST (Chumanov et al. 2011; Schache et al. 2012; Thelen et al. 2005). Disparities have also been observed in the magnitude and/or timing of the medial versus lateral hamstrings activation during running (Higashihara et al. 2010; Jonhagen et al. 1996; Silder et al. 2010b). Despite these findings, there are still many aspects that remain unexplored. For example, temporal coordination between hamstrings MTU kinematics (stretch or velocity) and activation during running has not been formally evaluated. This type of analysis, however, has been completed during walking both for healthy adults (Pedotti 1977; Winter and Scott 1991) and for children with cerebral palsy (Crenna 1998, 1999, 2003). Crenna (1998, 1999, 2003) performed a series of studies investigating lower-limb neuromuscular patterns in spastic diplegic gait, and rather interestingly found the motor output from the medial hamstrings during terminal swing to be specifically linked to changes in hamstrings MTU lengthening velocity. Based on these observations for walking, it is reasonable to suggest that temporal coordination between hamstrings MTU kinematics and activation might also exist during running. Hamstrings activation during running appears to start during terminal swing prior to when the hamstrings 
MTU is most elongated and end during terminal stance or initial swing prior to when the hamstrings MTU is most shortened (Silder et al. 2010b; Simonsen et al. 1985; Wood 1987), but such phase relations are yet to be quantified. Understanding temporal coordination between hamstrings MTU kinematics and activation during running is likely important, as such information may have potential implications regarding function and injury. For example, when a muscle begins to activate before maximum MTU stretch, active elongation can be expected to occur and the MTU has the potential to perform negative work. Because acute muscle strain-type injury is thought to be associated with eccentric contractions (Garrett et al. 1984; Garrett 1996), systematic shifts in the relative timing between MTU stretch and activation under different locomotion conditions (e.g. faster running) may therefore reflect the preference of the MTU to perform negative work and perhaps its propensity for injury.

In the present study, experimental recordings of whole-body kinematics and electromyographic (EMG) activity were obtained from a group of human participants running at a range of discrete steady-state speeds. Kinematic data were used in conjunction with a three-dimensional musculoskeletal model to measure MTU stretch and velocity for the biarticular hamstrings (SM, $\mathrm{ST}$ and $\mathrm{BF}^{\mathrm{LH}}$ ), while EMG data were used to determine the magnitude and timing of activation for the medial and lateral hamstrings. Our aim was to determine how: (1) the magnitude of MTU stretch, MTU velocity and activation; and (2) the relative timing between MTU kinematics and activation differed with increasing running speed and across the biarticular hamstrings.

\section{Methods}


Seven participants ( 5 males; 2 females) who were experienced sprinting athletes were voluntarily recruited. The study was approved by the relevant institutional Human Research Ethics Committees, and all participants gave their written informed consent prior to testing. At the time of testing, none of the participants were suffering from any musculoskeletal injury that was considered likely to adversely affect their running mechanics. Participants had a mean \pm 1 SD age of $26.6 \pm 8.3$ years, height of $177.9 \pm 5.6 \mathrm{~cm}$, and body mass of $74.4 \pm 8.2 \mathrm{~kg}$.

\section{Experimental data collection}

Data collection took place on an indoor $110 \mathrm{~m}$ synthetic running track. Myoelectric data were recorded at a sampling rate of $1500 \mathrm{~Hz}$ using a telemetered EMG system (Noraxon Telemyo 2400 G2, Noraxon USA Inc., Scottsdale, AZ, USA), while kinematic data were acquired using a three-dimensional motion analysis system (VICON, Oxford Metrics Ltd., Oxford, UK) with 22 cameras sampling at $250 \mathrm{~Hz}$. Ground reaction forces were measured at a sampling rate of 1500 Hz from eight force-plates (Kistler Instrument Corp., Amherst, NY, USA) embedded in the laboratory floor immediately adjacent to each other.

Participants wore athletic shorts and running sandals (Nike Straprunner IV, Beaverton, OR, USA) for testing. A single lower-limb was nominated as the test limb, and pairs of bipolar silver/silver chloride surface electrodes (Nicolet Biomedical Inc., Madison, WI, USA) were mounted over the posterior aspect of the thigh for the test limb. Each electrode had a $10 \mathrm{~mm}$ diameter contact area and there was a fixed distance of $20 \mathrm{~mm}$ between a pair of electrodes. Skin preparation and electrode placement were carried out in accordance with SENIAM guidelines 
(Hermens et al. 2000). For the medial hamstrings, surface electrodes were positioned on the midpoint of a line connecting the ischial tuberosity and the medial tibial epicondyle, while for the lateral hamstrings surface electrodes were positioned on the midpoint of a line connecting the ischial tuberosity and the lateral tibial epicondyle. It was assumed that the surface electrodes over the medial hamstrings recorded EMG activity originating from ST and SM. Similarly, it was assumed that the surface electrodes over the lateral hamstrings recorded EMG activity originating from $\mathrm{BF}^{\mathrm{LH}}$ and $\mathrm{BF}^{\mathrm{SH}}$. A ground electrode (3M electrosurgical plate: $3 \mathrm{M}$ Health Care, St. Paul, MN, USA) was placed over the proximal end of the anteromedial shaft of the tibia. Electrode cables were fixed to the skin with adhesive tape (Fixomull stretch, BSN Medical) and a tubular elastic net bandage (Surgifix, Smith and Nephew Pty Ltd) was placed over the thigh in order to minimise any motion artefacts.

A total of 50 reflective markers $(14 \mathrm{~mm})$ were mounted at specific anatomical locations on each participant's trunk, arms and lower-limbs. An initial static trial was captured with the participant assuming a neutral upright standing pose with all reflective markers in situ. All participants then completed a warm-up comprised of repeated walking and slow jogging trials in order to become fully accustomed to the experimental conditions. Experimental data were collected at four target running speeds: $3.5 \mathrm{~m} / \mathrm{s}, 5.0 \mathrm{~m} / \mathrm{s}, 7.0 \mathrm{~m} / \mathrm{s}$ and maximum sprinting $(\geq 7.9 \mathrm{~m} / \mathrm{s})$. The running speed conditions were tested in an incremental order. For each trial, participants were required to maintain a steady-state speed throughout the calibrated measurement field. No restrictions were placed on acceleration and deceleration distances. Running speed was recorded using timing gates (Speedlight Telemetry Timing, Swift Performance Equipment, Walcol, Queensland, Australia) positioned $20 \mathrm{~m}$ apart at each end of the calibrated measurement field. Repeated trials were performed until a successful trial was captured for each running speed condition. A 
successful trial was one in which: (i) the measured speed was within $\pm 5 \%$ of the particular target speed; and (ii) simultaneous ground reaction force, kinematic and EMG data were recorded for a complete stride cycle for the designated test limb. Adequate recovery time was provided between running speed increments so as to avoid the effects of fatigue.

\section{Measurement of MTU kinematics}

Data describing hamstring MTU kinematics during running were computed by utilising a generic three-dimensional musculoskeletal model (Fig. 1(a)) available in OpenSim software (Delp et al. 2007; Dorn et al. 2012). The model was comprised of 12 body segments and 31 degrees-offreedom. The geometrical properties (i.e. muscle attachment points and lines-of-action) of the muscles in the model were identical with those utilised by Dorn et al. (2012). For each participant, the generic musculoskeletal model was scaled to match their individual anthropometry (Delp et al. 2007).

An optimisation-based inverse kinematics analysis was performed to derive a set of model-based coordinate values that best reproduced the experimentally recorded marker trajectories. The optimisation problem was to minimise the sum of the squared differences between the musculoskeletal model's virtual marker locations and the measured marker locations, whilst satisfying the model's set of kinematic joint constraints (Lu and O'Connor 1999). Lower-limb joint angles were calculated and smoothed using a $4^{\text {th }}$ order Butterworth filter with a cut-off frequency of $8 \mathrm{~Hz}$. The hamstring muscle complex was represented in the musculoskeletal model by three biarticular muscles (SM, ST and $\left.\mathrm{BF}^{\mathrm{LH}}\right)$ and one uniarticular muscle $\left(\mathrm{BF}^{\mathrm{SH}}\right)$. The present study analysed data for the biarticular hamstrings only. The SM, ST and $\mathrm{BF}^{\mathrm{LH}}$ muscles were 
modelled as a series of line segments from origin to insertion, with via points used to wrap the path of each muscle about the posterior aspect of the knee joint (Fig. 1(b) and (c)).

The kinematic parameters of interest were MTU stretch and MTU velocity. MTU length $\left(L^{\mathrm{MTU}}\right)$ was equal to the distance of the path from origin to insertion of the MTU, taking into account wrapping near the knee joint. Changes in $L^{\mathrm{MTU}}$ (i.e. stretch) were calculated as a percentage of the anatomical reference MTU length $\left(L_{0}{ }^{\mathrm{MTU}}\right)$, which was defined as the $L^{\mathrm{MTU}}$ during the static standing calibration trial (Fig 1(b)). In the absence of knowing the $L^{\mathrm{MTU}}$ that corresponded to the mid-point of the force-length plateau, it was decided to adopt an approach for defining $L_{0}{ }^{\mathrm{MTU}}$ that was consistent with previous studies (Chumanov et al. 2011; Thelen et al. 2005). Positive stretch represented an increase in $L^{\mathrm{MTU}}$ with respect to $L_{0}{ }^{\mathrm{MTU}}$, whereas negative stretch represented a decrease in $L^{\mathrm{MTU}}$ with respect to $L_{0}{ }^{\mathrm{MTU}}$. MTU velocity $\left(V^{\mathrm{MTU}}\right)$ was calculated as the first derivative of $L^{\mathrm{MTU}}$ with respect to time; that is, $V^{\mathrm{MTU}}=d L^{\mathrm{MTU}} / d t$. MTU velocity was divided by $L_{0}{ }^{\mathrm{MTU}}$ in order to express $V^{\mathrm{MTU}}$ in anatomical reference MTU lengths per second, or $L_{0}{ }^{\mathrm{MTU}} / \mathrm{s}$. Positive $V^{\mathrm{MTU}}$ represented the rate at which the MTU lengthened, whereas negative $V^{\mathrm{MTU}}$ represented the rate at which the MTU shortened.

\section{EMG data processing}

EMG data were processed using a dual-pass, forward-reverse, $2^{\text {nd }}$ order Butterworth filter. To produce a linear envelope, EMG data were high-pass filtered at $20 \mathrm{~Hz}$, full-wave rectified, and then low-pass filtered at $20 \mathrm{~Hz}$. The choice of cut-off frequency for the low-pass filter was based on that which produced a linear envelope that adequately profiled the dominant bursts without becoming sensitive to artifact bursts. The start and end times of EMG activity with respect to the 
stride cycle were initially determined using an algorithm, whereby a valid activation period was defined to be at least $150 \mathrm{~ms}$ in duration and have a magnitude greater than three standard deviations of the baseline level of activity. The start and end times obtained from this algorithm were then checked and adjusted, where required, based on visual inspection of both the raw EMG data and the linear envelope. To ensure that there was no bias in determining start and end times, EMG data for a given trial were analysed independently (i.e., a single muscle for a single participant at a single running speed) with no reference to stride cycle events or to the findings from other trials. EMG duty cycle was defined as the proportion of the stride cycle that the hamstrings were activated. For each period of continuous hamstrings activation, EMG magnitude was determined by calculating both the mean of the linear envelope as well as the area underneath the linear envelope (i.e. the integrated value). These two parameters were quantified because it was considered likely that with increasing running speed a given period of hamstring activation could change both in terms of magnitude and duration. Hence, the mean would provide an indication of a change in magnitude only, while the integrated value would also take into account any time-dependent modifications in the linear envelope. Both parameters were normalised to the linear envelope 'grand' mean (i.e., the mean of all the valid periods of EMG activity over the stride cycle) obtained from the maximum running speed trial for the particular hamstring muscle. This method of normalising the magnitude of the EMG data was chosen to minimise inter-participant variability (Yang and Winter 1984). It also ensured that there was no inconsistency in testing conditions (lower limb joint angles; positions of surface electrodes relative to underlying muscle fibres and motor points) between the dynamic running data and the normalisation data.

\section{Data analysis}


The instants of foot-strike and toe-off were determined from the ground reaction force data. A single complete stride cycle (i.e. ipsilateral foot-strike to the following ipsilateral foot-strike) that contained simultaneously recorded kinematic and EMG data for the designated test limb was identified for each running speed for each participant. Group mean curves were generated displaying MTU stretch for the biarticular hamstrings over the full stride cycle, and these data were plotted for each running speed. Similar group mean curves were generated for MTU velocity. Data for hamstrings MTU kinematics and activation were plotted together for comparative purposes. Temporal coordination between hamstrings MTU stretch and activation was evaluated by adopting an approach similar to that used by Hodson-Tole and Wakeling (2010). The duration (in ms) between the start of EMG activity and the time of maximum MTU stretch represented the activation phase relation, whereas the duration (in ms) between the end of EMG activity and the time of minimum MTU stretch represented the deactivation phase relation. Temporal coordination between hamstrings MTU velocity and activation was evaluated by comparing the start and end times of EMG activity with the time of reversal or inflection points on the MTU velocity profile.

Various discrete parameters were extracted from the dataset for statistical analysis. All parameters of interest (except for parameters describing EMG magnitude) were compared using two-way repeated-measures ANOVA tests, including post hoc one-way repeated-measures ANOVA tests and paired $t$-tests where a significant main effect or interaction was found. The mean and integrated values of the linear envelope for each period in the stride cycle when hamstrings activation was observed were compared using one-way repeated-measures ANOVA tests, including post hoc paired $t$-tests where a significant main effect was found. These 
parameters were compared between running speeds only as the adopted approach for normalising the magnitude of the EMG data inherently limited the ability to compare between hamstring muscles (i.e. medial versus lateral hamstrings activation). The statistical association between certain discrete parameters and running speed was explored using linear regression and calculating the coefficient of determination $\left(\mathrm{R}^{2}\right)$. All statistical tests were performed using IBM SPSS Statistics version 20 (IBM Corporation, New York, USA). A conservative level of significance was set at $p \leq 0.01$.

\section{Results}

Mean $\pm 1 \mathrm{SD}$ running speeds for the cohort were $3.4 \pm 0.1 \mathrm{~m} / \mathrm{s}, 5.0 \pm 0.1 \mathrm{~m} / \mathrm{s}, 6.9 \pm 0.1 \mathrm{~m} / \mathrm{s}$ and $9.0 \pm 0.7 \mathrm{~m} / \mathrm{s}$. As running speed increased, the duration of the stride cycle progressively decreased (Fig. 2). Mean $\pm 1 S D$ stride cycle times were $0.76 \pm 0.02$ s, $0.70 \pm 0.03$ s, $0.59 \pm 0.02$ s and $0.47 \pm 0.02$ $\mathrm{s}$ and mean $\pm 1 \mathrm{SD}$ stance times were $0.24 \pm 0.2 \mathrm{~s}, 0.19 \pm 0.02 \mathrm{~s}, 0.15 \pm 0.01 \mathrm{~s}$ and $0.12 \pm 0.01 \mathrm{~s}$ for each incremental running speed, respectively. Hamstrings MTU stretch and activation data at each running speed for a single participant are displayed in Fig. 2.

\section{MTU stretch}

The general profile of MTU stretch plotted over the stride cycle was similar for all biarticular hamstring muscles and for all running speeds (Fig. 3, left panels). Data describing the magnitudes of maximum MTU stretch and peak-to-peak MTU stretch for the hamstrings at each running speed are contained in Table 1. The largest maximum MTU stretch of $12.1 \pm 2.5 \%$

occurred for $\mathrm{BF}^{\mathrm{LH}}$ at a running speed of $6.9 \pm 0.1 \mathrm{~m} / \mathrm{s}$. Maximum MTU stretch displayed a 
significant main effect for running speed $(p<0.001)$ but not for hamstring muscle $(p=0.011)$, while there was a significant interaction between running speed and hamstring muscle $(p<0.001)$. When running speed changed from $3.4 \pm 0.1 \mathrm{~m} / \mathrm{s}$ to $5.0 \pm 0.1 \mathrm{~m} / \mathrm{s}$, maximum MTU stretch significantly increased for all of the hamstrings ( $p=0.001$, all cases). For running speeds beyond $5.0 \pm 0.1 \mathrm{~m} / \mathrm{s}$, maximum MTU stretch for SM and ST did not significantly change $(p \geq 0.020)$, whereas maximum MTU stretch for $\mathrm{BF}^{\mathrm{LH}}$ significantly increased between $5.0 \pm 0.1 \mathrm{~m} / \mathrm{s}$ and $6.9 \pm 0.1 \mathrm{~m} / \mathrm{s}(p=0.004)$ but not between $6.9 \pm 0.1 \mathrm{~m} / \mathrm{s}$ and $9.0 \pm 0.7 \mathrm{~m} / \mathrm{s}(p=0.146)$. Maximum MTU stretch was not significantly different between the hamstrings when running at $3.4 \pm 0.1 \mathrm{~m} / \mathrm{s}$ and $5.0 \pm 0.1 \mathrm{~m} / \mathrm{s}(p \geq 0.016$, all cases). However, when running at $6.9 \pm 0.1 \mathrm{~m} / \mathrm{s}$ and $9.0 \pm 0.7 \mathrm{~m} / \mathrm{s}$, maximum MTU stretch was found to be significantly greater for SM and $\mathrm{BF}^{\mathrm{LH}}$ compared to ST ( $p \leq 0.005$, all cases), with no significant difference evident between $\mathrm{SM}$ and $\mathrm{BF}^{\mathrm{LH}}(p \geq 0.020$, all cases). The largest peak-to-peak MTU stretch of $26.3 \pm 1.6 \%$ occurred for ST at a running speed of $6.9 \pm 0.1 \mathrm{~m} / \mathrm{s}$. Peak-to-peak MTU stretch displayed significant main effects for running speed $(p<0.001)$ and hamstring muscle $(p<0.001)$ as well as a significant interaction between running speed and hamstring muscle $(p<0.001)$. For all of the hamstrings, peak-to-peak MTU stretch significantly increased between $3.4 \pm 0.1 \mathrm{~m} / \mathrm{s}$ and $5.0 \pm 0.1 \mathrm{~m} / \mathrm{s}(p<0.001$, all cases $)$ and between $5.0 \pm 0.1 \mathrm{~m} / \mathrm{s}$ and $6.9 \pm 0.1 \mathrm{~m} / \mathrm{s}(p \leq 0.004$, all cases $)$ but not between $6.9 \pm 0.1 \mathrm{~m} / \mathrm{s}$ and $9.0 \pm 0.7 \mathrm{~m} / \mathrm{s}$ ( $p \geq 0.210$, all cases). For each running speed, peak-to-peak MTU stretch was significantly different between the hamstrings ( $p \leq 0.003$, all cases), being largest for ST and smallest for $\mathrm{BF}^{\mathrm{LH}}$.

\section{MTU velocity}

The general profile of MTU velocity plotted over the stride cycle was similar for all biarticular hamstring muscles and for all running speeds (Fig. 3, right panels). Data describing the 
magnitude of the peak MTU shortening and lengthening velocity for the hamstrings at each running speed are contained in Table 1 . The largest peak MTU shortening velocity of $-2.2 \pm 0.2$ $L_{0}{ }^{\mathrm{MTU}} / \mathrm{s}$ occurred for ST at the fastest running speed. Both the peak MTU shortening velocity during stance and the peak MTU shortening velocity during swing displayed significant main effects for running speed $(p<0.001)$ and hamstring muscle $(p<0.001)$ as well as a significant interaction between running speed and hamstring muscle $(p<0.001)$. The largest peak MTU lengthening velocity of $2.2 \pm 0.3 L_{0} \mathrm{MTU} / \mathrm{s}$ occurred for both $\mathrm{ST}$ and $\mathrm{BF}^{\mathrm{LH}}$ at the fastest running speed. Peak MTU lengthening velocity displayed a significant main effect for running speed $(p<0.001)$ but not for hamstring muscle $(p=0.057)$, while there was a significant interaction between running speed and hamstring muscle $(p=0.001)$. For $\mathrm{BF}^{\mathrm{LH}}$, peak MTU lengthening velocity significantly increased with each running speed increment ( $p=0.002$, all cases), whereas for ST and SM significant increases were only observed when running speed progressed beyond $5.0 \pm 0.1 \mathrm{~m} / \mathrm{s}(p \leq 0.001$, all cases $)$. Peak MTU lengthening velocity was significantly different between the hamstrings only at a running speed of $6.9 \pm 0.1 \mathrm{~m} / \mathrm{s}(p \leq 0.004$, all cases), being largest for $\mathrm{BF}^{\mathrm{LH}}$ and smallest for SM.

\section{Activation}

There were two main periods in the stride cycle when hamstrings activation was observed (Fig. 3): during the first third of the stride cycle from foot-strike through to terminal stance or initial swing (referred to herein as the $1^{\text {st }}$ period); and during the final third of the stride cycle from terminal swing through to foot-strike (referred to herein as the $2^{\text {nd }}$ period). Note that this result occurred because EMG activity was analysed between two consecutive ipsilateral foot-strikes for the test limb. It should be kept in mind that the hamstrings displayed a single burst of EMG 
activity that commenced in terminal swing of one stride cycle and ceased in terminal stance or initial swing of the next stride cycle (Fig. 2).

For both periods in the stride cycle when EMG activity was observed, the mean and integrated values of the medial and lateral hamstrings linear envelope displayed significant main effects for running speed ( $p<0.001$, all cases). These parameters progressively increased in magnitude with faster running, although not all running speed increments were associated with statistically significant changes (Fig. 4). When comparing the slowest to the fastest running speed, the mean of the medial hamstrings linear envelope increased 4.7 -fold and 3.5 -fold for the $1^{\text {st }}$ and $2^{\text {nd }}$ periods, respectively, whilst the mean of the lateral hamstrings linear envelope increased 5.0-fold and 4.0-fold for the $1^{\text {st }}$ and $2^{\text {nd }}$ periods, respectively (Fig. 4, top panels). Mean \pm 1 SD EMG duty cycles for the medial hamstrings were $55.7 \pm 10.0 \%, 54.4 \pm 6.8 \%, 59.0 \pm 6.4 \%$ and $61.9 \pm 6.5 \%$ and for the lateral hamstrings were $49.1 \pm 3.9 \%, 50.6 \pm 5.1 \%, 52.2 \pm 5.8 \%$ and $55.0 \pm 2.3 \%$ for each incremental running speed, respectively. Statistical analysis of EMG duty cycle demonstrated a significant main effect for hamstring muscle $(p=0.005)$ but not for running speed $(p=0.058)$, and there was no significant interaction between running speed and hamstring muscle $(p=0.776)$. While the EMG duty cycle for the medial hamstrings was longer than that for the lateral hamstrings for all running speeds, none of the post hoc inter-muscle comparisons reached significance ( $p \geq 0.041$, all cases).

\section{Temporal coordination between MTU stretch and activation}

Except for a single participant at the slowest running speed, hamstrings activation ended before the time of minimum MTU stretch during initial swing (Fig. 3, left panels). The absolute 
magnitude of the deactivation phase relation duration decreased with faster running (Fig. 5, top panel). A significant linear relationship was found between the deactivation phase relation duration and running speed for $\mathrm{SM}\left(\mathrm{R}^{2}=0.402 ; p=0.000\right), \mathrm{ST}\left(\mathrm{R}^{2}=0.397 ; p=0.000\right)$ and $\mathrm{BF}^{\mathrm{LH}}$ $\left(\mathrm{R}^{2}=0.698 ; p=0.000\right)$. However, the ANOVA test did not reveal a significant main effect for running speed $(p=0.012)$ or hamstring muscle $(p=0.122)$, and there was no significant interaction between running speed and hamstring muscle $(p=0.564)$.

Hamstrings activation always started before the time of maximum MTU stretch during terminal swing (Fig. 3, left panels). The absolute magnitude of the activation phase relation duration decreased with faster running for $\mathrm{BF}^{\mathrm{LH}}$, but not for SM and ST (Fig. 5, bottom panel). A significant linear relationship was found between the activation phase relation duration and running speed for $\mathrm{BF}^{\mathrm{LH}}\left(\mathrm{R}^{2}=0.519 ; p<0.001\right)$, whereas no such relationship was found for SM $\left(\mathrm{R}^{2}=0.043 ; p=0.288\right)$ or $\mathrm{ST}\left(\mathrm{R}^{2}=0.053 ; p=0.237\right)$. However, the ANOVA test did not reveal a significant main effect for running speed $(p=0.072)$ or hamstring muscle $(p=0.041)$, and there was no significant interaction between running speed and hamstring muscle $(p=0.207)$.

Active MTU stretch during terminal swing

As hamstrings activation always started before the time of maximum MTU stretch during terminal swing, the amount of MTU stretch that took place during the activation phase relation (i.e., active MTU stretch) was calculated. It ranged from $1.6 \%$ to $14.7 \%$ for SM, $1.6 \%$ to $14.5 \%$ for $\mathrm{ST}$, and $0.2 \%$ to $5.6 \%$ for $\mathrm{BF}^{\mathrm{LH}}$ across all participants and all running speeds (Fig. 6). The amount of active MTU stretch displayed a significant main effect for hamstring muscle $(p=0.008)$ but not for running speed $(p=0.407)$, and there was no significant interaction between hamstring 
muscle and running speed $(p=0.147)$. At the two fastest running speeds, the amount of active MTU stretch for $\mathrm{BF}^{\mathrm{LH}}$ was smaller than that for SM and ST, although neither of these comparisons reached statistical significance ( $p \geq 0.017$, both cases). The amount of active MTU stretch expressed as a proportion of peak-to-peak MTU stretch ranged from $6.1 \%$ to $59.0 \%$ for SM, $5.9 \%$ to $55.8 \%$ for ST, and $1.0 \%$ to $32.3 \%$ for $\mathrm{BF}^{\mathrm{LH}}$.

\section{Temporal coordination between MTU velocity and activation}

A peak occurred in the hamstrings MTU shortening velocity profile during initial swing around the same time as activation ended, especially with faster running (Fig. 3, right panels). The times (expressed as \% stride cycle) for these two events were compared for each hamstring muscle separately (Fig 7, top panels). For SM and ST, the ANOVA test did not reveal a significant main effect for time ( $p=0.017$, both cases) or running speed ( $p>0.047$, both cases), and there was no significant interaction between time and running speed ( $p>0.155$, both cases). For $\mathrm{BF}^{\mathrm{LH}}$, the ANOVA test demonstrated a significant main effect for time $(p=0.011)$ as well as running speed $(p=0.003)$, and there was a significant interaction between time and running speed $(p=0.001)$.

Post hoc tests showed that there was a significant difference in time between the peak in the $\mathrm{BF}^{\mathrm{LH}}$ MTU shortening velocity during initial swing and the end of lateral hamstrings EMG activity when running at $3.4 \pm 0.1 \mathrm{~m} / \mathrm{s}(p=0.001)$ and $5.0 \pm 0.1 \mathrm{~m} / \mathrm{s}(p=0.006)$, but not when running at $6.9 \pm 0.1 \mathrm{~m} / \mathrm{s}(p=0.011)$ and $9.0 \pm 0.7 \mathrm{~m} / \mathrm{s}(p=0.403)$.

A small inflection point in the hamstrings MTU lengthening velocity profile coincided with the start of activation during terminal swing (Fig. 3, right panels). The times for these two events were compared for each hamstring muscle separately (Fig. 7, bottom panels). A significant main 
effect for time was not found for SM $(p=0.693), \operatorname{ST}(p=0.588)$ or $\mathrm{BF}^{\mathrm{LH}}(p=0.540)$. A significant main effect was found for running speed for SM $(p=0.010)$ and $\mathrm{BF}^{\mathrm{LH}}(p<0.001)$ but not for ST $(p=0.011)$. Finally, a significant interaction between time and running speed was not evident for any of the hamstrings ( $p \geq 0.095$, all cases).

\section{Discussion}

The human biarticular hamstrings (SM, ST and $\left.\mathrm{BF}^{\mathrm{LH}}\right)$ are known to have a number of distinguishing architectural and geometrical characteristics, including differences in anatomical configuration (Kumazaki et al. 2012; Woodley and Mercer 2005), muscle-fibre length and PCSA (Kellis et al. 2012; Ward et al. 2009), as well as lines-of-action and moment-arm magnitudes (Arnold et al. 2000; Buford et al. 1997; Herzog and Read 1993). The present study expands upon this knowledge by providing a comprehensive analysis of the neuro-mechanical behaviour of the $\mathrm{ST}, \mathrm{SM}$ and $\mathrm{BF}^{\mathrm{LH}}$ during running. Our specific aim was to determine how the magnitude and timing of parameters such as MTU stretch, MTU velocity and activation changed as running speed increased, and whether these parameters differed across the biarticular hamstrings.

Before discussing the results there are some limitations associated with the current study that ought to be highlighted. First, only a single stride cycle was analysed per speed condition for each participant. It often took many attempts for a participant to achieve all the requirements for a successful trial at a given running speed. In order to prevent fatigue from influencing running mechanics, we were unable to obtain multiple successful trials for all participants, especially at fast running speeds. However, we do not believe that our main findings would differ if multiple stride cycles per running speed for each participant were analysed; for one of the participants we 
were able to record data for two consecutive stride cycles for each running speed and minimal stride-to-stride variability was evident in the pattern of EMG activity and MTU stretch (Fig. 2). Second, data were captured from a relatively small sample of participants. It is therefore possible that some of the non-significant findings (e.g. activation phase relation durations and amount of active MTU stretch) represent a type-two error. Third, we used a scaled-generic musculoskeletal model to calculate hamstrings MTU kinematics, thus model geometry in the present study was not truly subject-specific. Nevertheless, the sagittal plane hip and knee joint moment arms for the hamstrings in the model are generally consistent with moment arm data obtained from direct measurements on cadavers (Schache et al. 2012) and living subjects (Schache et al. 2013). Furthermore, it has been demonstrated that differences amongst models in the representation of musculoskeletal geometry do not substantially influence estimations of hamstrings MTU length during locomotion (Arnold et al. 2001). Fourth, the knee was modelled as a translating hinge joint (Yamaguchi and Zajac 1989), which meant that any potential effect that knee axial rotation had on hamstring MTU kinematics was not taken into account. The non-invasive measurement of knee axial rotation was avoided due to known issues with soft tissue artefact (Akbarshahi et al. 2010; Reinschmidt et al. 1997). However, this limitation was not considered of great concern, as changes in knee axial rotation orientation were unlikely to have been appreciable given that running mainly involves movement in the sagittal plane. In support of this notion, it has recently been shown using dual plane fluoroscopy that the amplitude of in vivo knee axial rotation during slow running is only small throughout terminal swing and stance (Goyal et al. 2012). We therefore do not believe that our results for hamstrings MTU stretch and velocity would have been substantially influenced by the inclusion of knee axial rotation kinematics. Fifth, we measured MTU kinematics only. The degree to which MTU stretch comprised of lengthening of the muscle fibre versus the series elastic elements (e.g., tendon) was not determined. It is 
possible to measure muscle-fibre strain for a contracting muscle in vivo using ultrasound imaging (Farris and Sawicki 2012; Lichtwark and Wilson 2006), and the application of this technique to investigate human hamstring muscle function during locomotion would be a valuable direction for future research. Sixth, the issue of crosstalk when using surface electrodes meant that it was not possible to confidently record the independent EMG activities of ST, SM and $\mathrm{BF}^{\mathrm{LH}}$. Hamstrings EMG activity was therefore separated into 'medial' and 'lateral' components only. Finally, our results regarding the magnitude of hamstring activation are limited to the particular EMG normalisation method. The need to normalise recorded EMG data is undisputed; however, there is a lack of consensus regarding the most appropriate normalisation method (Burden 2010). In the present study, both the mean and the integrated values of the linear envelope for a given running speed were normalised to the linear envelope 'grand' mean (i.e., the mean of the two periods in the stride cycle when EMG activity was observed) obtained from the maximum running speed trial for the particular hamstring muscle (medial/lateral) and participant. While this normalisation method minimised inter-participant variability (Yang and Winter 1984), it inherently limited the ability to directly compare the magnitude of activation between the medial and lateral hamstring muscles. Our results need to be interpreted in light of these limitations.

\section{Effect of running speed on hamstrings MTU stretch, velocity and activation}

Measurements of hamstrings MTU stretch and velocity in this study generally concur with prior research. Magnitudes for maximum change in MTU length for SM, ST and BF ${ }^{\mathrm{LH}}$ were reported by Thelen et al. (2005) to be $7.7 \pm 1.5 \%, 8.4 \pm 1.7 \%$ and $9.8 \pm 2.8 \%$, respectively, and by Chumanov et al. (2011) to be $11.0 \pm 2.0 \%, 11.0 \pm 2.0 \%$ and $13.0 \pm 2.0 \%$, respectively. In the present study, magnitudes for maximum change in MTU length for SM, ST and $\mathrm{BF}^{\mathrm{LH}}$ were $10.3 \pm 1.3 \%$, 
$9.2 \pm 1.4 \%$ and $12.1 \pm 2.5 \%$, respectively (Table 1). A common finding therefore is that $\mathrm{BF}^{\mathrm{LH}}$ experiences the largest maximum MTU stretch of all the biarticular hamstrings, being elongated by up to $13 \%$ of its $L_{0}{ }^{\mathrm{MTU}}$ during fast running. Peak MTU lengthening velocities of $1.7 \pm 0.3$ $L_{0}^{\mathrm{MTU}} / \mathrm{s}, 1.9 \pm 0.3 L_{0}^{\mathrm{MTU}} / \mathrm{s}, 1.8 \pm 0.3 L_{0}{ }^{\mathrm{MTU}} / \mathrm{s}$ for SM, ST and $\mathrm{BF}^{\mathrm{LH}}$, respectively, were reported by Thelen et al. (2005). Equivalent data from the current study were slightly greater in magnitude, with peak MTU lengthening velocities of $2.0 \pm 0.2 L_{0} \mathrm{MTU} / \mathrm{s}, 2.2 \pm 0.3 L_{0}^{\mathrm{MTU}} / \mathrm{s}$ and $2.2 \pm 0.3 L_{0} \mathrm{MTU} / \mathrm{s}$ recorded for $\mathrm{SM}, \mathrm{ST}$ and $\mathrm{BF}^{\mathrm{LH}}$, respectively (Table 1).

Increasing running speed had a different effect on hamstrings MTU stretch compared to velocity. Maximum MTU stretch and peak-to-peak MTU stretch increased with faster running, but only up to a running speed of $6.9 \pm 0.1 \mathrm{~m} / \mathrm{s}$, after which both parameters decreased slightly (Table 1 ; Fig 3 , left panels). Thelen et al. (2005) also found negligible change in hamstrings maximum MTU stretch when running speed was increased from $80 \%$ to $100 \%$ of maximum. Hence, the magnitude of hamstrings MTU stretch appears to remain relatively constant as running speed approaches near maximal levels in humans. In contrast, hamstrings peak MTU shortening and lengthening velocities steadily increased in absolute magnitude with each running speed increment (Table 1; Fig. 3, right panels), a finding also reported by Thelen et al. (2005). The sensitivity of peak MTU velocity to an increase in running speed was therefore primarily a consequence of the progressive decrease in stride cycle duration.

An increase in MTU stretch can be produced by a combination of both muscle-fibre lengthening as well as elongation of the compliant series elastic elements (e.g., tendon). The extent to which an increase in MTU stretch reflects underlying lengthening strain of the muscle fibre versus tendon is known to vary for lower-limb muscles with differing morphologies. For example, 
muscle fibre and tendon strains have been measured in vivo for the human medial gastrocnemius (a distal leg muscle) during running at speeds ranging from $2.0 \mathrm{~m} / \mathrm{s}$ to $3.25 \mathrm{~m} / \mathrm{s}$ (Farris and Sawicki 2012; Lichtwark and Wilson 2006). The strain profile of the MTU throughout stance was found to be primarily a product of the spring-like behaviour of the Achilles tendon, as the medial gastrocnemius muscle fibres actually shortened by a small amount. In the context of the present study, it is of interest to understand whether proximal leg muscles such as the hamstrings operate in a similar fashion. While data describing in vivo muscle fibre and tendon strains during running do not exist for the human hamstrings, many studies have recorded muscle-fibre strain (via sonomicrometry) during locomotion for homologous limb muscles in a wide variety of animals, including the SM muscle in dogs (Gregersen et al. 1998) as well as the BF muscle in rats (Gillis and Biewener 2001) and goats (Gillis et al. 2005). For all modes of locomotion (i.e. walking, trotting and galloping), these studies found muscle-fibre length to increase throughout swing, remain relatively constant during initial stance, and then decrease throughout mid to terminal stance. Peak lengthening strain typically occurred during terminal swing just prior to foot-strike. It is interesting to note that this pattern of strain over the stride cycle is qualitatively similar to that observed in the present study for hamstrings MTU stretch across all speeds of running (Fig. 3, left panels). Further research is therefore required to quantify the relationship between MTU stretch and muscle-fibre strain for the human hamstring muscles during running.

Medial and lateral hamstrings EMG activity progressively increased in magnitude with each running speed increment for both periods of the stride cycle when hamstrings activation was observed (Fig. 4); however, EMG duty cycle remained relatively constant (Fig. 3). Greater activation intensity with faster running was not unexpected, and is in agreement with the findings from previous studies (Higashihara et al. 2010; Kyröläinen et al. 2005; Mero and Komi 1987; 
Silder et al. 2010b). At each running speed, the magnitude of the integrated value for both the medial and lateral hamstrings linear envelope was found to be greater for the $1^{\text {st }}$ period of the stride cycle compared to the $2^{\text {nd }}$ period (Fig. 4 , bottom panels), which was primarily due to the $1^{\text {st }}$ period having a longer duration than the $2^{\text {nd }}$ period (Fig. 3). An interesting finding was that for both the medial and lateral hamstrings the integrated value of the linear envelope significantly increased in magnitude between running speeds of $6.9 \pm 0.1 \mathrm{~m} / \mathrm{s}$ and $9.0 \pm 0.7 \mathrm{~m} / \mathrm{s}$ for the $1^{\text {st }}$ period of the stride cycle when hamstrings activation was observed but not for the $2^{\text {nd }}$ period (Fig. 4 , bottom panels). This difference may be explained on the basis of the muscle force-length and/or force-velocity relationship. With regards to the $1^{\text {st }}$ period, MTU shortening velocities during initial stance and initial swing significantly increased in magnitude with faster running (Table 1; Fig. 3, right panels). If at least an equivalent level of hamstrings force was required at this time in the stride cycle at all running speeds, then the force-velocity relationship implies that a much larger volume of activated muscle would be needed with faster running to offset the effect of increasing MTU shortening velocities. It has been previously demonstrated for turkey ankle extensor muscles that an increase in muscle shortening velocity with faster locomotion is associated with an increase in the volume of active muscle required to produce a given force (Gabaldón et al. 2008). With regards to the $2^{\text {nd }}$ period, maximum MTU stretch occurred during this stage of the stride cycle for each hamstring muscle (Fig. 3, left panels). Studies investigating the relationship between MTU length, EMG activity, and torque for the human hamstrings have demonstrated that with increased MTU length, less EMG activity is required to produce an equivalent torque (Lunnen et al. 1981; Mohamed et al. 2002). Hence, our results might suggest that with faster running the hamstrings become increasingly less efficient (decreased force per unit cross-sectional area of active muscle) for the $1^{\text {st }}$ period of the stride cycle (i.e. during stance/initial swing) compared to the $2^{\text {nd }}$ period (i.e. during terminal swing). 
With the exception of a single participant running at the slowest speed, hamstrings activation ended before the time of minimum MTU stretch during initial swing, and thus group mean deactivation phase relations were negative in polarity at all running speeds (Fig. 5, upper panel). Hodson-Tole and Wakeling (2010) measured the deactivation phase relation for rat ankle extensor muscles at increasing speeds of treadmill locomotion. The durations of the deactivation phase relation were around $-100 \mathrm{~ms}$ at a speed of $20 \mathrm{~cm} / \mathrm{s}$. Deactivation phase relation durations were negative in polarity at slow speeds, and became smaller in absolute magnitude with faster locomotion until switching to become positive in polarity at a speed of $40 \mathrm{~cm} / \mathrm{s}$. Despite contrasting muscles and species, it is interesting that the pattern observed by these investigators (i.e. a shift from negative towards positive polarity for deactivation phase relations with increasing locomotion speed) is somewhat similar to that found in the present study for the human hamstrings with faster running. At maximal running speeds, it is highly unlikely that the hamstring muscle fibres will have enough time to fully relax and cease force production before MTU elongation begins, suggesting that the hamstrings MTU probably performs a degree of negative work during the deactivation period.

Hamstrings activation always started before the time of maximum MTU stretch during terminal swing (Fig 3, left panels; Fig. 5, lower panel). The absolute magnitude of the activation phase relation durations ranged from $40.2 \mathrm{~ms}$ to $159.5 \mathrm{~ms}, 38.1 \mathrm{~ms}$ to $155.8 \mathrm{~ms}$, and $10.9 \mathrm{~ms}$ to 106.0 $\mathrm{ms}$ for the $\mathrm{SM}, \mathrm{ST}$ and $\mathrm{BF}^{\mathrm{LH}}$ muscles, respectively. If these activation phase relation durations are interpreted in light of available data describing the timing of neural activation relative to the onset of muscle force development, then it would seem likely that the hamstring muscle fibres commenced force generation during terminal swing prior to the time of maximum MTU stretch. 
Simultaneous recordings of in vivo EMG activity and muscle force during functional activities have been obtained from certain species. One example is the pectoralis muscle in birds, where it has been shown that the time delay between the onset of EMG activity and the onset of muscle force development is no longer than $10 \mathrm{~ms}$ (Biewener et al. 1998; Hedrick et al. 2003; Soman et al. 2005). In the context of the current study, the pectoralis muscle in birds represents a skeletal muscle acting on a swinging (or non-weight bearing) limb that begins activating towards the end of its lengthening phase, thus its function in this regard may be considered somewhat analogous to the way the human hamstrings operate during the terminal swing phase of running. Because muscle fibres likely developed force prior to the time of maximum MTU stretch during terminal swing, the hamstrings MTU can be expected to perform negative work at this stage of the stride cycle as well.

The onset of hamstrings EMG activity towards the end of the MTU lengthening phase during terminal swing for running is consistent with what has been previously observed for walking. For example, Pedotti (1977) obtained data from seven healthy adults walking at a speed of $\sim 1.4 \mathrm{~m} / \mathrm{s}$, and found hamstrings EMG activity to start when MTU length reached a relative maximal value. The onset of EMG activity during terminal swing was therefore suggested to be under the influence of a reflex regulation from 1a afferents. Such a situation would also seem plausible for running. The likely function of the stretch-related activation of the hamstrings is to modulate knee joint kinematics; specifically, to oppose the rapid acceleration of the knee joint into extension during the terminal swing phase of the stride cycle (Dorn et al. 2012). This assertion is supported by the fact that hamstrings EMG activity was observed to start at $\sim 80 \%$ of the stride cycle (Fig. 8, bottom panels), which was just after the time when peak hip flexion occurred 
( $\sim 5 \%$ of the stride cycle) but well before the time when peak knee extension occurred ( $\sim 95 \%$ of the stride cycle).

It has been previously reported that the onset of hamstrings EMG activity during terminal swing for walking occurs immediately prior to peak MTU lengthening velocity, and that this temporal coordination is not influenced by a change in speed (Crenna 1999). While we found the onset of hamstrings activation during terminal swing for running to occur after the time of peak MTU lengthening velocity (Fig. 3, right panels), we did find close time coupling between the onset of hamstrings activation and an identifiable inflection point in the MTU lengthening velocity profile, which was also independent of speed (Fig. 7, bottom panels). When our findings are interpreted together with those of Crenna (1999), good evidence is available demonstrating that irrespective of locomotion speed temporal coordination between neural activation and MTU velocity for the human hamstring muscles does occur, especially during the terminal swing phase of the stride cycle.

\section{Differences in the neuro-mechanical behaviour amongst the human biarticular hamstrings}

We observed a number of differences in the neuro-mechanical behaviour amongst the human biarticular hamstrings during running. For instance, maximum MTU stretch relative to $L_{0}{ }^{\mathrm{MTU}}$ was found to be largest for $\mathrm{BF}^{\mathrm{LH}}$, whereas peak-to-peak MTU stretch and peak MTU shortening velocity were largest for ST (Table 1; Fig. 3). Such findings are likely to be predominantly a manifestation of differences in the geometrical representation of the biarticular hamstrings in the model; namely, differences in the specified attachment sites and MTU paths that propagated to small variations in the sagittal plane hip and knee moment arm magnitudes. The hip extensor 
moment arm was largest for $\mathrm{ST}$ and $\mathrm{BF}^{\mathrm{LH}}$ (both of a similar magnitude) and smallest for SM, while the knee flexor moment arm was largest for ST and smallest for $\mathrm{BF}^{\mathrm{LH}}$. Maximum MTU stretch occurred during the terminal swing phase of the stride cycle (Fig 2; Fig 3, left panel) when the mean hip flexion angle was between $22.1^{\circ}$ to $52.4^{\circ}$ and the mean knee flexion angle was between $3.6^{\circ}$ to $32.9^{\circ}$ (depending upon running speed). With the lower-limb orientated in this way, maximum MTU stretch was largest for $\mathrm{BF}^{\mathrm{LH}}$ because it was lengthened by just as much as ST and more so than SM with hip flexion, and it was not shortened by as much as ST and SM with knee flexion (Thelen et al. 2005). As ST had the largest hip extensor and knee flexor moment arm, its MTU length was highly sensitive to a change in hip and knee joint orientation, and thus ST was found to exhibit the greatest peak-to-peak MTU stretch and peak MTU shortening velocity of all the biarticular hamstrings. Ultimately though, in vivo hamstrings MTU kinematic behaviour during running is likely to be determined by the complex interaction amongst a number of factors, including (but not limited to) muscle-tendon architecture, pattern of activation as well as geometry.

At the two fastest running speeds, $\mathrm{BF}^{\mathrm{LH}}$ had a smaller duration for the activation phase relation and a smaller amount of active MTU stretch during the terminal swing phase of the stride cycle when compared to SM and ST (Fig. 5, bottom panel; Fig. 6). Muscle force development during the MTU lengthening phase (and thus any potential negative work performed) might therefore have been reduced for the lateral relative to the medial hamstrings. It is well known that muscles are most susceptible to contraction-induced damage when they are activated and simultaneously lengthened (Garrett 1996; McCully and Faulkner 1985), and that under in vivo conditions active MTU stretch of $\sim 5 \%$ can be sufficient to induce such damage (Butterfield and Herzog 2005). Hence, if our results are taken at face value, it would appear that $\mathrm{BF}^{\mathrm{LH}}$ has a lesser likelihood for 
contraction-induced damage (and perhaps injury) than SM and ST for healthy participants completing fast steady-state running. However, such a conclusion is inconsistent with clinical observations, where it has been well documented that hamstring muscle strain-type injuries most commonly involve $\mathrm{BF}^{\mathrm{LH}}$ (De Smet and Best 2000; Koulouris and Connell 2003). A possible explanation for this discrepancy could be that neuro-mechanical behaviour is altered during the stride cycle in which an injury occurs. Perhaps under certain circumstances the lateral hamstrings commence activation too early and are suddenly required to perform an unusually large amount of negative work. Another plausible explanation could be that muscle-fibre mechanics is of greater relevance in generating insights into strain-type injuries than MTU mechanics. For example, it has been recently demonstrated that when the $\mathrm{BF}^{\mathrm{LH}}$ muscle contracts eccentrically localised regions of high tissue strains develop immediately adjacent to its proximal muscletendon junction, a site where injury is often observed (Fiorentino et al. 2012; Silder et al. 2010a). Clearly, further research is required before the pathophysiological factors behind hamstring muscle strain-type injuries are fully understood.

In conclusion, the present study measured the neuro-mechanical behaviour of the human biarticular hamstrings across a range of running speeds. While the general profiles for MTU stretch and velocity over the stride cycle were similar for all running speeds, the absolute magnitude of various discrete parameters (e.g. maxima and minima) for MTU stretch and velocity significantly increased with faster running, with the increase being more substantial for parameters describing MTU velocity than stretch. There were two main periods in the stride cycle when hamstrings activation was observed: a period from foot-strike through to terminal stance or initial swing and a period from terminal swing through to foot-strike. The total duration of both periods (EMG duty cycle) expressed as a proportion of the stride cycle did not change as 
running speed increased. However, the magnitude of activation for the medial and lateral hamstrings did significantly increase with faster running for both periods. In almost all instances, hamstrings activation ended prior to the time of minimum MTU stretch during initial swing, and it always started prior to the time of maximum MTU stretch during terminal swing. A number of key differences were evident amongst the biarticular hamstrings: (i) maximum MTU stretch was largest for $\mathrm{BF}^{\mathrm{LH}}$ and smallest for ST, whereas the opposite was true for peak-to-peak MTU stretch; (ii) ST displayed the largest peak MTU shortening velocity; (iii) EMG duty cycle for the medial hamstrings was longer than that for the lateral hamstrings; and (iv) for the two fastest running speeds the duration of the activation phase relation and the amount of active MTU stretch

during terminal swing were both smaller for $\mathrm{BF}^{\mathrm{LH}}$ compared to SM and ST. Further insight into the neuro-mechanical behaviour of the hamstrings during running could be gained by quantifying the relative contribution of muscle fibre versus tendon elongation to MTU stretch, and determining whether or not the duration of the activation phase relation amongst the hamstrings changes for alternative motor tasks and is a relevant factor for understanding susceptibility to acute muscle strain-type injury.

\section{Acknowledgements}

Financial support for this study was provided by the Physiotherapy Research Foundation Tagged Sports Physiotherapy Australia Research Grant (T08-THE/SPA(1)018), the Australian Research Council Discovery Projects Grant DP0772838, the Australian Research Council Linkage Projects Grant LP110100262, and a Victorian Endowment for Science, Knowledge and Innovation (VESKI) Fellowship to MGP. The authors wish to thank Mr Doug Rosemond for his assistance with experimental data collection. 


\section{References}

Akbarshahi M, Schache AG, Fernandez JW, Baker R, Banks S, Pandy MG (2010) Non-invasive assessment of soft-tissue artifact and its effect on knee joint kinematics during functional activity. J Biomech 43 (7):1292-1301

Arnold AS, Blemker SS, Delp SL (2001) Evaluation of a deformable musculoskeletal model for estimating muscle-tendon lengths during crouch gait. Ann Biomed Eng 29 (3):263-274

Arnold AS, Salinas S, Asakawa DJ, Delp SL (2000) Accuracy of muscle moment arms estimated from MRI-based musculoskeletal models of the lower extremity. Comput Aided Surg 5 (2):108-119

Biewener AA, Corning WR, Tobalske BW (1998) In vivo pectoralis muscle force-length behaviour during level flight in pigeons (Columba livia). J Exp Biol 201 (Pt 24):32933307

Buford WL, Ivey FM, Malone JD, Patterson RM, Peare GL, Nguyen DK, Stewart AA (1997) Muscle balance at the knee: moment arms for the normal knee and the ACL-minus knee. IEEE Trans Rehabil Eng 5 (4):367-379

Burden A (2010) How should we normalise electromyograms obtained from healthy participants? What we have learned from over 25 years of research. J Electromyogr Kinesiol 20 (6):1023-1035

Butterfield TA, Herzog W (2005) Quantification of muscle fiber strain during in vivo repetitive stretch-shortening cycles. J Appl Physiol 99 (4):593-602

Chumanov ES, Heiderscheit BC, Thelen DG (2011) Hamstring musculotendon dynamics during stance and swing phases of high-speed running. Med Sci Sports Exerc 43 (3):525-532 
Crenna P (1998) Spasticity and 'spastic' gait in children with cerebral palsy. Neurosci Biobehav Rev $22(4): 571-578$

Crenna P (1999) Pathophysiology of lengthening contractions in human spasticity: a study of the hamstring muscles during locomotion. Pathophysiology 5 (4):283-297

Crenna P (2003) Assessment of spasticity during unperturbed (loco)motor tasks in children with cerebral palsy. Dev Med Child Neurol 45 (5):30-31

De Smet AA, Best TM (2000) MR Imaging of the distribution and location of acute hamstring injuries in athletes. Am J Roentgenol 174 (2):393-399

Delp SL, Anderson FC, Arnold AS, Loan P, Habib A, John CT, Guendelman E, Thelen DG (2007) OpenSim: open-source software to create and analyze dynamic simulations of movement. IEEE Trans Biomed Eng 54 (11):1940-1950

Dorn TW, Schache AG, Pandy MG (2012) Muscular strategy shift in human running: dependence of running speed on hip and ankle muscle performance. J Exp Biol 215 (Pt 11):1944-1956

Farris DJ, Sawicki GS (2012) Human medial gastrocnemius force-velocity behavior shifts with locomotion speed and gait. Proc Natl Acad Sci USA 109 (3):977-982

Fiorentino NM, Epstein FH, Blemker SS (2012) Activation and aponeurosis morphology affect in vivo muscle tissue strains near the myotendinous junction. J Biomech 45 (4):647-652

Gabaldón AM, Nelson FE, Roberts TJ (2008) Relative shortening velocity in locomotor muscles: turkey ankle extensors operate at low V/V $\mathrm{V}_{\max }$. Am J Physiol Regul Integr Comp Physiol 294 (1):R200-R210

Garrett WE (1996) Muscle strain injuries. Am J Sports Med 24 (6):S2-S8

Garrett WE, Califf JC, Bassett FH (1984) Histochemical correlates of hamstring injuries. Am J Sports Med 12 (2):98-103 
Gillis GB, Biewener AA (2001) Hindlimb muscle function in relation to speed and gait: in vivo patterns of strain and activation in a hip and knee extensor of the rat (rattus norvegicus). $\mathbf{J}$ Exp Biol 204 (Pt 15):2717-2731

Gillis GB, Flynn JP, McGuigan P, Biewener AA (2005) Patterns of strain and activation in the thigh muscles of goats across gaits during level locomotion. J Exp Biol 208 (Pt 24):45994611

Goyal K, Tashman S, Wang JH, Li K, Zhang X, Harner C (2012) In vivo analysis of the isolated posterior cruciate ligament-deficient knee during functional activities. Am J Sports Med 40 (4):777-785

Gregersen CS, Silverton NA, Carrier DR (1998) External work and potential for elastic storage at the limb joints of running dogs. J Exp Biol 201 (Pt 23):3197-3210

Hedrick TL, Tobalske BW, Biewener AA (2003) How cockatiels (Nymphicus hollandicus) modulate pectoralis power output across flight speeds. J Exp Biol 206 (Pt 8):1363-1378

Hermens HJ, Freriks B, Disselhorst-Klug C, Rau G (2000) Development of recommendations for SEMG sensors and sensor placement procedures. J Electromyogr Kinesiol 10 (5):361-371

Herzog W, Read LJ (1993) Lines of action and moment arms of the major force-carrying structures crossing the human knee joint. J Anat 182 (Pt 2):213-230

Higashihara A, Ono T, Kubota J, Okuwaki T, Fukubayashi T (2010) Functional differences in the activity of the hamstring muscles with increasing running speed. J Sports Sci 28 (10):1085-1092

Hodson-Tole EF, Wakeling JM (2010) The influence of strain and activation on the locomotor function of the rat extensor muscles. J Exp Biol 213 (Pt 2):318-330

Jonhagen S, Ericson MO, Nemeth G, Eriksson E (1996) Amplitude and timing of electromyographic activity during sprinting. Scand J Med Sci Sports 6 (1):15-21 
Kellis E, Galanis N, Kapetanos G, Natsis K (2012) Architectural differences between the hamstring muscles. J Electromyogr Kinesiol 22 (4):520-526

Koulouris G, Connell D (2003) Evaluation of the hamstring muscle complex following acute injury. Skeletal Radiol 32 (10):582-589

Kumazaki T, Ehara Y, Sakai T (2012) Anatomy and physiology of hamstring injury. Int J Sports Med 33 (12):950-954

Kyröläinen H, Avela J, Komi PV (2005) Changes in muscle activity with increasing running speed. J Sports Sci 23 (10):1101-1109

Lichtwark GA, Wilson AM (2006) Interactions between the human gastrocnemius muscle and the Achilles tendon during incline, level and decline locomotion. J Exp Biol 209 (Pt 21):4379-4388

Lu TW, O'Connor JJ (1999) Bone position estimation from skin marker coordinates using global optimisation with joint constraints. J Biomech 32 (2):129-134

Lunnen JD, Yack J, Leveau BF (1981) Relationship between muscle length, muscle activity, and torque of the hamstring muscles. Phys Ther 61 (2):190-195

McCully KK, Faulkner JA (1985) Injury to skeletal muscle fibers of mice following lengthening contractions. J Appl Physiol 59 (1):119-126

Mero A, Komi PV (1987) Electromyographic activity in sprinting at speeds ranging from submaximal to supra-maximal. Med Sci Sports Exerc 19 (3):266-274

Mohamed O, Perry J, Hislop H (2002) Relationship between wire EMG activity, muscle length, and torque of the hamstrings. Clin Biomech 17 (8):569-579

Pedotti A (1977) A study of motor coordination and neuromuscular activities in human locomotion. Biological Cybernetics 26 (1):53-62 
Reinschmidt C, van den Bogert AJ, Nigg BM, Lundberg A, Murphy N (1997) Effect of skin movement on the analysis of skeletal knee joint motion during running. J Biomech 30 (7):729-732

Schache AG, Ackland DC, Fok L, Koulouris G, Pandy MG (2013) Three-dimensional geometry of the human biceps femoris long head measured in vivo using magnetic resonance imaging. Clin Biomech 28 (3):278-284

Schache AG, Dorn TW, Blanch PD, Brown NAT, Pandy MG (2012) Mechanics of the human hamstring muscles during sprinting. Med Sci Sports Exerc 44 (4):647-658

Silder A, Reeder SB, Thelen DG (2010a) The influence of prior hamstring injury on lengthening muscle tissue mechanics. J Biomech 43 (12):2254-2260

Silder A, Thelen DG, Heiderscheit BC (2010b) Effects of prior hamstring strain on strength, flexibility, and running mechanics. Clin Biomech 25 (7):681-686

Simonsen EB, Thomsen L, Klausen K (1985) Activity of mono- and biarticular leg muscles during sprint running. Eur J Appl Physiol Occup Physiol 54 (5):524-532

Soman A, Hedrick TL, Biewener AA (2005) Regional patterns of pectoralis fascicle strain in the pigeon Columba livia during level flight. J Exp Biol 208 (Pt 4):771-786

Thelen DG, Chumanov ES, Hoerth DM, Best TM, Swanson SC, Li L, Young M, Heiderscheit B (2005) Hamstring muscle kinematics during treadmill sprinting. Med Sci Sports Exerc 37 (1):108-114

Ward SR, Eng CM, Smallwood LH, Lieber RL (2009) Are current measurements of lower extremity muscle architecture accurate? Clin Orthop Rel Res 467 (4):1074-1082

Winter DA, Scott SH (1991) Technique for interpretation of electromyography for concentric and eccentric contractions in gait. J Electromyogr Kinesiol 1 (4):263-269 
Wood GA (1987) Biomechanical limitations to sprint running. In: Van Gheluwe B, Atha J (eds)

Current Research in Sports Biomechanics. Medicine and Sport Science, Volume 25.

Karger, Basel, pp 58-71

Woodley SJ, Mercer SR (2005) Hamstring muscles: architecture and innervation. Cells Tissues Organs 179 (3):125-141

Yamaguchi GT, Zajac FE (1989) A planar model of the knee joint to characterise the knee extensor mechanism. J Biomech 22 (1):1-10

Yang JF, Winter DA (1984) Electromyographic amplitude normalization methods: improving their sensitivity as diagnostic tools in gait analysis. Arch Phys Med Rehabil 65 (9):517521
Abbreviations
$\mathrm{BF} \quad$ Biceps femoris
$\mathrm{BF}^{\mathrm{LH}} \quad$ Biceps femoris long head
$\mathrm{BF}^{\mathrm{SH}} \quad$ Biceps femoris short head
EMG Electromyographic
$L^{\mathrm{MTU}} \quad$ Muscle-tendon unit length
$L_{0}{ }^{\mathrm{MTU}} \quad$ Anatomical reference muscle-tendon unit length
m Metres
ms Milliseconds
MTU Muscle-tendon unit
PCSA Physiological cross-sectional area
s $\quad$ Seconds 


$\begin{array}{ll}\text { SM } & \text { Semimembranosus } \\ \text { ST } & \text { Semitendinosus } \\ t & \text { Time } \\ V^{\text {MTU }} & \text { Muscle-tendon unit velocity }\end{array}$

\section{Figure Captions}

Fig. 1 The three-dimensional musculoskeletal model used in this study to calculate hamstrings MTU kinematics during running. (A): The skeleton was represented as a multi-body linkage containing 11 degrees-of-freedom. (B) and (C): The SM, ST and BF ${ }^{\mathrm{LH}}$ muscles were modelled as a series of line segments from origin to insertion, with via points used to wrap the path of each muscle about the posterior aspect of the knee joint. For clarity, only $\mathrm{BF}^{\mathrm{LH}}$ for the right lowerlimb is shown. Muscle-tendon unit length $\left(L^{\mathrm{MTU}}\right)$ was equal to the distance of the path from origin to insertion of the MTU. Changes in $L^{\mathrm{MTU}}$ (i.e. stretch) during running (C) were calculated as a percentage of the anatomical reference MTU length $\left(L_{0}{ }^{\mathrm{MTU}}\right)$, which was defined as the $L^{\mathrm{MTU}}$ during the static standing calibration trial (B).

Fig. 2 Hamstrings MTU stretch and activation for two consecutive stride cycles recorded from a single participant. The left hand panels display EMG activity recorded from the medial hamstrings and MTU stretch for semimembranosus (thin solid black lines) and semitendinosus (thin dashed black lines). The right hand panels display EMG activity recorded from the lateral hamstrings and MTU stretch for biceps femoris long head (thin solid black lines). In all panels, data for EMG activity are presented at two stages through the signal filtering process: first, after being high-pass filtered at $20 \mathrm{~Hz}$ (grey wavy lines) and; second, after being full-wave rectified 
and then low-pass filtered at $20 \mathrm{~Hz}$, i.e. the linear envelope (thick solid black lines). The stance phase is indicated by a vertical grey shaded bar. Note that the running speeds indicated are those for the single participant, and hence they differ slightly in magnitude to the group mean $\pm 1 \mathrm{SD}$ running speeds.

Fig. 3 Group mean curves for hamstring MTU stretch (left panels) and MTU velocity (right panels) with increasing running speed. In each panel, the thin solid black line represents semimembranosus, the thin dashed black line represents semitendinosus, and the thick solid black line represents biceps femoris long head. All data are time normalised as a percentage of a single full stride cycle. The stance phase is indicated by a vertical grey shaded bar. The horizontal bars at the top of each panel represent the two periods in the stride cycle when hamstrings activation was observed. The solid black horizontal bars depict the mean \pm 1 SD durations of medial hamstrings EMG activity, whereas the open horizontal bars depict the mean \pm 1 SD durations of lateral hamstrings EMG activity.

Fig. 4 Effect of increasing running speed on the magnitude of EMG activity for the medial (left panels) and lateral (right panels) hamstring muscles. The top row (left and right panels) contains the mean of the linear envelope, whereas the bottom row (left and right panels) contains the integrated value of the linear envelope. The solid black vertical bars represent the $1^{\text {st }}$ period in the stride cycle when hamstrings activation was observed (i.e. from foot-strike through to terminal stance or initial swing). The open vertical bars represent the $2^{\text {nd }}$ period in the stride cycle when hamstrings activation was observed (i.e. from terminal swing through to foot-strike). Significant $(p \leq 0.01)$ within-muscle, between-speed differences in the magnitude of hamstrings 
EMG activity are indicated by the horizontal lines and asterisk. Running speeds are: (1) $3.4 \pm 0.1$ $\mathrm{m} / \mathrm{s}$; (2) $5.0 \pm 0.1 \mathrm{~m} / \mathrm{s}$; (3) $6.9 \pm 0.1 \mathrm{~m} / \mathrm{s}$; (4) $9.0 \pm 0.7 \mathrm{~m} / \mathrm{s}$.

Fig. 5 Phase relations between MTU stretch and activation for each running speed and for each hamstring muscle. The top panel displays the duration (ms) between the time when EMG activity ended and the time of minimum MTU stretch during initial swing (deactivation phase relation). A positive value represented EMG activity ending after the time of minimum MTU stretch, whereas a negative value represented EMG activity ending before the time of minimum MTU stretch. The bottom panel displays the duration (ms) between the time when EMG activity started and the time of maximum MTU stretch during terminal swing (activation phase relation). A positive value represented EMG activity starting after the time of maximum MTU stretch, whereas a negative value represented EMG activity starting before the time of maximum MTU stretch. The solid black vertical bars describe the mean \pm 1 SD phase relation between medial hamstrings EMG activity and semimembranosus (SM) MTU stretch. The grey solid vertical bars describe the mean \pm 1 SD phase relation between medial hamstrings EMG activity and semitendinosus (ST) MTU stretch. The open vertical bars describe the mean $\pm 1 \mathrm{SD}$ phase relation between lateral hamstrings EMG activity and biceps femoris long head $\left(\mathrm{BF}^{\mathrm{LH}}\right) \mathrm{MTU}$ stretch.

Fig. 6 The amount of active MTU stretch (\%) that occurred during the terminal swing phase of the stride cycle for each running speed and for each hamstring muscle. The solid black vertical bars describe the mean $\pm 1 \mathrm{SD}$ amount of active MTU stretch for semimembranosus (SM). The grey solid vertical bars describe the mean \pm 1 SD amount of active MTU stretch for semitendinosus (ST). The open vertical bars describe the mean $\pm 1 \mathrm{SD}$ amount of active MTU stretch for biceps femoris long head $\left(\mathrm{BF}^{\mathrm{LH}}\right)$. 
Fig. 7 The temporal coordination between hamstrings MTU velocity and activation during running. The top row displays the time (\% stride cycle) when EMG activity ended versus the time (\% stride cycle) when the peak in MTU shortening velocity occurred during initial swing. The top left panel compares medial hamstrings EMG and semimembranosus (SM) MTU velocity; the top middle panel compares medial hamstrings EMG and semitendinosus (ST) MTU velocity; the top right panel compares lateral hamstrings EMG and biceps femoris long head $\left(\mathrm{BF}^{\mathrm{LH}}\right)$ MTU velocity. The bottom row displays the time (\% stride cycle) when EMG activity started versus the time (\% stride cycle) when the small inflection point in the MTU lengthening velocity profile occurred during terminal swing. The bottom left panel compares medial hamstrings EMG and SM MTU velocity; the bottom middle panel compares medial hamstrings EMG and ST MTU velocity; the bottom right panel compares lateral hamstrings EMG and $\mathrm{BF}^{\mathrm{LH}}$ MTU velocity. Significant $(p \leq 0.01)$ differences in time are indicated by the horizontal lines and asterisk. Running speeds are: (1) $3.4 \pm 0.1 \mathrm{~m} / \mathrm{s}$; (2) $5.0 \pm 0.1 \mathrm{~m} / \mathrm{s}$; (3) $6.9 \pm 0.1 \mathrm{~m} / \mathrm{s}$; (4) $9.0 \pm 0.7 \mathrm{~m} / \mathrm{s}$.

Table 1 Mean \pm 1 SD values for the magnitude of MTU stretch and MTU velocity for the biarticular hamstrings.

\begin{tabular}{|c|c|c|c|c|c|}
\hline \multirow[t]{2}{*}{ Parameter } & \multirow[t]{2}{*}{ Muscle } & \multicolumn{4}{|c|}{ Running speed } \\
\hline & & (1) $3.4 \pm 0.1 \mathrm{~m} / \mathrm{s}$ & (2) $5.0 \pm 0.1 \mathrm{~m} / \mathrm{s}$ & (3) $6.9 \pm 0.1 \mathrm{~m} / \mathrm{s}$ & (4) $9.0 \pm 0.7 \mathrm{~m} / \mathrm{s}$ \\
\hline \multirow[t]{3}{*}{ Maximum stretch * } & (a) SM & $7.8 \pm 1.2^{2,3,4}$ & $9.3 \pm 1.3^{1}$ & $10.3 \pm 1.3^{1, b}$ & $9.4 \pm 1.4^{1, b}$ \\
\hline & (b) ST & $6.3 \pm 1.3^{2,3,4}$ & $7.9 \pm 1.51$ & $9.2 \pm 1.41, a, c$ & $8.3 \pm 1.5^{1, a, c}$ \\
\hline & (c) BFLH & $8.4 \pm 2.5^{2,3,4}$ & $10.4 \pm 2.9^{1,3}$ & $12.1 \pm 2.5^{1,2, b}$ & $11.5 \pm 2.5^{1, b}$ \\
\hline \multirow[t]{3}{*}{ Peak-to-peak stretch \# } & (a) SM & $19.2 \pm 1.1^{2,3,4, b, c}$ & $23.3 \pm 1.5^{1,3, b, c}$ & $25.4 \pm 1.5^{1,2, b, c}$ & $25.0 \pm 1.1^{1, b, c}$ \\
\hline & (b) ST & $19.6 \pm 1.2^{2,3,4, a, c}$ & $23.9 \pm 1.7^{1,3, a, c}$ & $26.3 \pm 1.6^{1,2, a, c}$ & $25.7 \pm 1.3^{1, a, c}$ \\
\hline & (c) BFLH & $16.9 \pm 1.5^{2,3,4, a, b}$ & $21.3 \pm 2.1_{1,3,4, a, b}$ & $23.8 \pm 1.7^{1,2, a, b}$ & $23.5 \pm 1.4^{1,2, a, b}$ \\
\hline \multirow[t]{2}{*}{ Peak stance shortening velocity \# } & (a) SM & $-0.8 \pm 0.1^{2,3,4, b, c}$ & $-1.0 \pm 0.1^{1,3,4, b, c}$ & $-1.2 \pm 0.1^{1,2, b}$ & $-1.3 \pm 0.1^{1,2}$ \\
\hline & (b) ST & $-0.9 \pm 0.12,3,4, a, c$ & $-1.1 \pm 0.1^{1,3,4, a, c}$ & $-1.3 \pm 0.1^{1,2, a}$ & $-1.4 \pm 0.2^{1,2}$ \\
\hline
\end{tabular}




\begin{tabular}{|c|c|c|c|c|c|}
\hline & (c) BFLH & $-0.8 \pm 0.12,3,4, a, a, b$ & $-1.0 \pm 0.11,3,4, \mathrm{a}, \mathrm{b}$ & $-1.2 \pm 0.1^{1,2,4}$ & $-1.4 \pm 0.1^{1,2,3}$ \\
\hline \multirow[t]{3}{*}{ Peak swing shortening velocity \# } & (a) SM & $-0.9 \pm 0.12,3,4, b, c$ & $-1.2 \pm 0.2^{1,3,4, b, c}$ & $-1.6 \pm 0.2^{1,2,4, b, c}$ & $-2.0 \pm 0.2^{1,2,3, \mathrm{~b}, \mathrm{c}}$ \\
\hline & (b) ST & $-0.9 \pm 0.1 \quad 2,3,4, a, c$ & $-1.3 \pm 0.2 \quad 1,3,4, a, c$ & $-1.8 \pm 0.2^{1,2,4, a, c}$ & $-2.2 \pm 0.2 \quad 1,2,3, \mathrm{a}, \mathrm{c}$ \\
\hline & (c) $\mathrm{BF}^{\mathrm{LH}}$ & $-0.7 \pm 0.1 \quad 2,3,4, a, b$ & $-1.0 \pm 0.1 \quad 1,3,4, a, b$ & $-1.3 \pm 0.2^{1,2,4, a, b}$ & $-1.6 \pm 0.2^{1,2,3, a, b}$ \\
\hline \multirow[t]{3}{*}{ Peak swing lengthening velocity * } & (a) SM & $1.0 \pm 0.2^{3,4}$ & $1.4 \pm 0.2^{3,4}$ & $1.7 \pm 0.2^{1,2,4, b, c}$ & $2.0 \pm 0.2^{1,2,3}$ \\
\hline & (b) ST & $1.1 \pm 0.2^{3,4}$ & $1.4 \pm 0.3^{3,4}$ & $1.9 \pm 0.3^{1,2,4, a, c}$ & $2.2 \pm 0.3^{1,2,3}$ \\
\hline & (c) BFLH & $0.9 \pm 0.1^{2,3,4}$ & $1.5 \pm 0.44^{1,3,4}$ & $2.0 \pm 0.3^{1,2,4, a, b}$ & $2.2 \pm 0.3^{1,2,3}$ \\
\hline
\end{tabular}

Data for MTU stretch are expressed as a percentage of the anatomical reference MTU length ( $\left.L_{0}^{\mathrm{MTU}}\right)$, which was defined as the $L^{M T U}$ during the static standing calibration trial. Data for MTU shortening and lengthening velocity are expressed in anatomical reference MTU lengths per second, or $L_{0} \mathrm{MTU} / \mathrm{s}$.

SM Semimembranosus; ST Semitendinosus; BF나 Biceps femoris long head

\# Significant ( $p \leq 0.01$ ) main effects found for (i) running speed, (ii) hamstring muscle, and (iii) running speed $\mathrm{x}$ hamstring muscle interaction

* Significant ( $p \leq 0.01$ ) main effects found for (i) running speed, and (ii) running speed $x$ hamstring muscle interaction;

$2,3,4$ Significantly different ( $p \leq 0.01$ ) from running speeds (2) i.e., $5.0 \pm 0.1 \mathrm{~m} / \mathrm{s}$, (3) i.e., $6.9 \pm 0.1 \mathrm{~m} / \mathrm{s}$, and (4) i.e., $9.0 \pm 0.7 \mathrm{~m} / \mathrm{s}$;

a,b Significantly different ( $p \leq 0.01)$ from hamstring muscle (a) i.e., semimembranosus (SM) and (b) i.e., semitendinosus (ST).
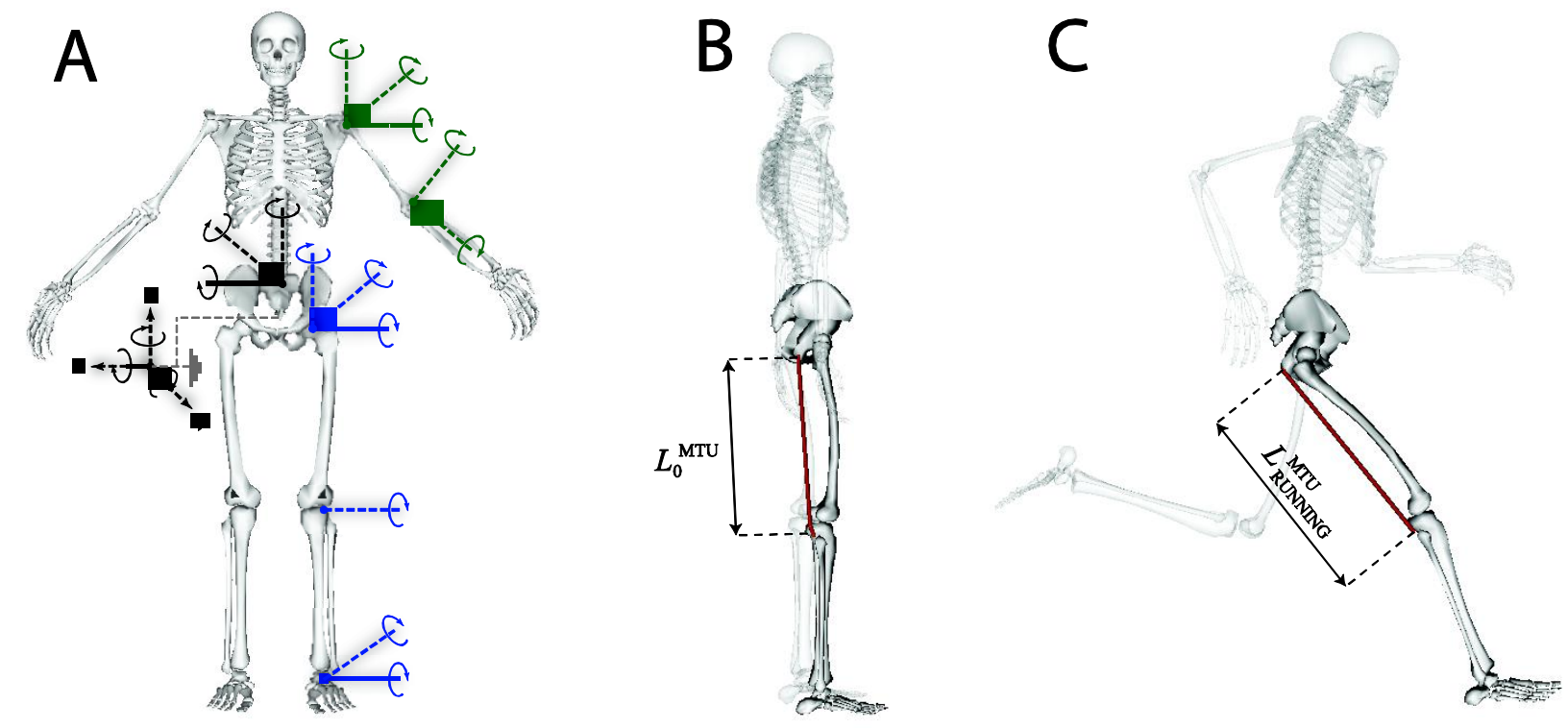
Medial hamstrings
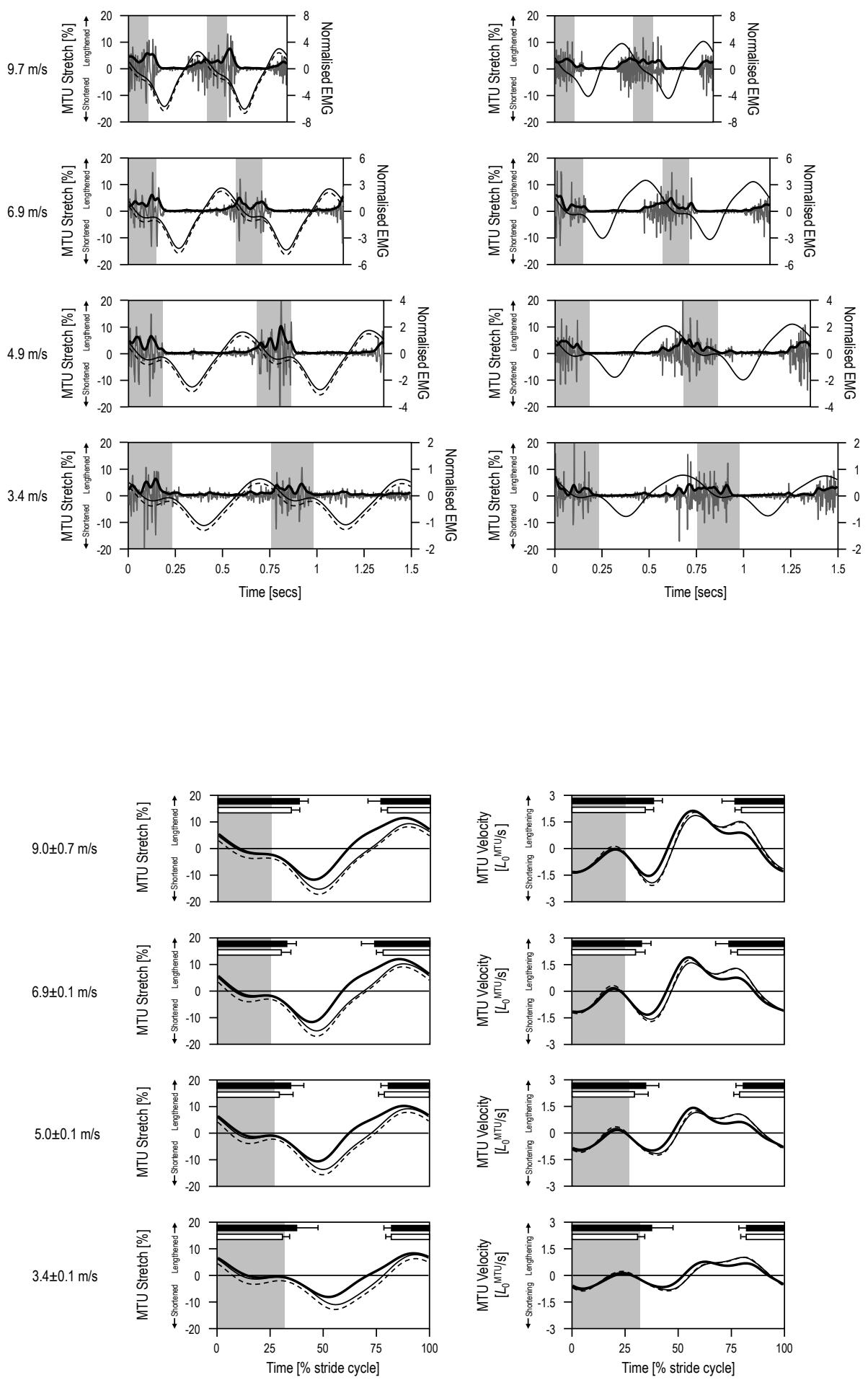

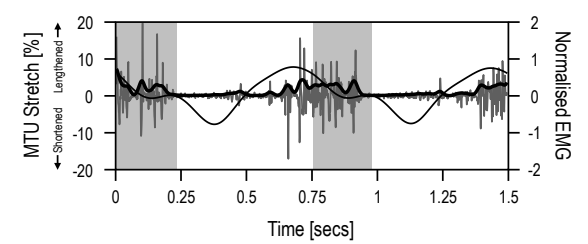



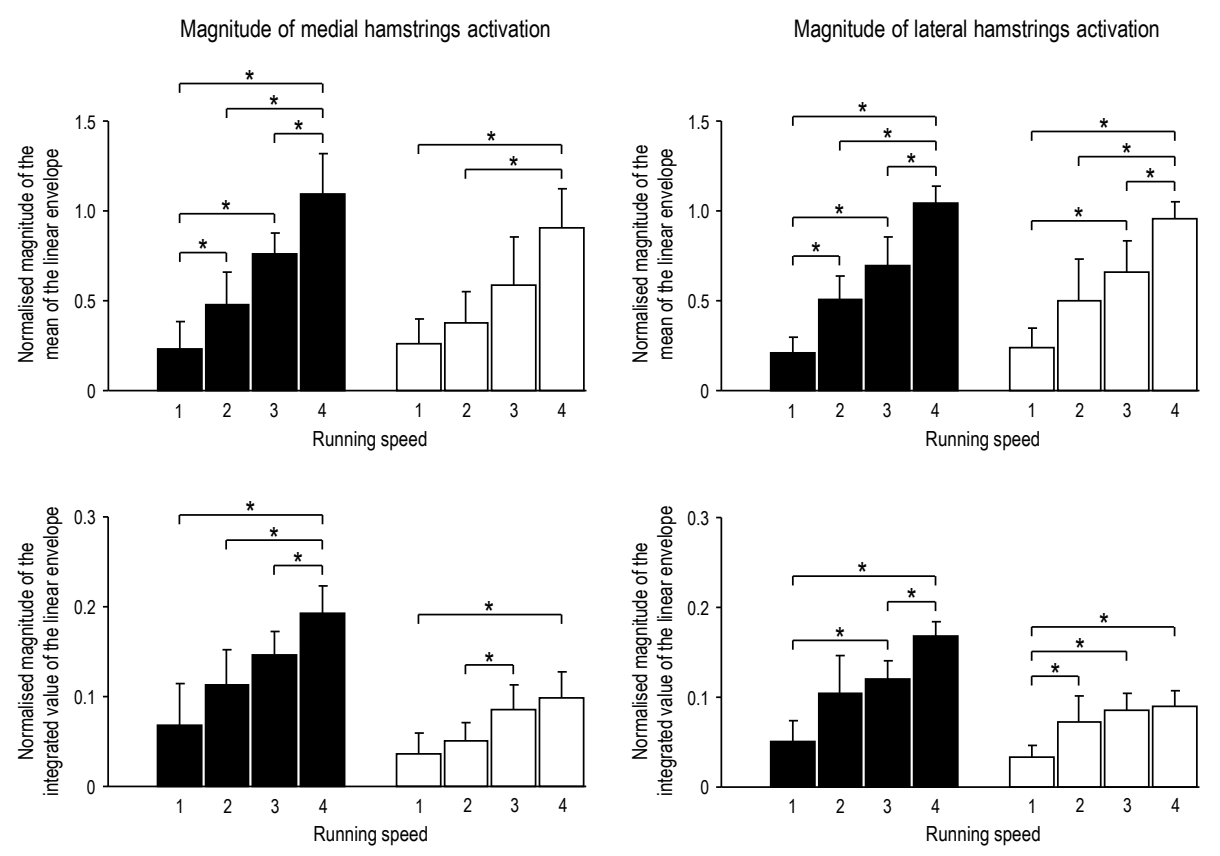

$1^{\text {st }}$ period of the stride cycle (stance/initial swing)

$2^{\text {nd }}$ period of the stride cycle (terminal swing)
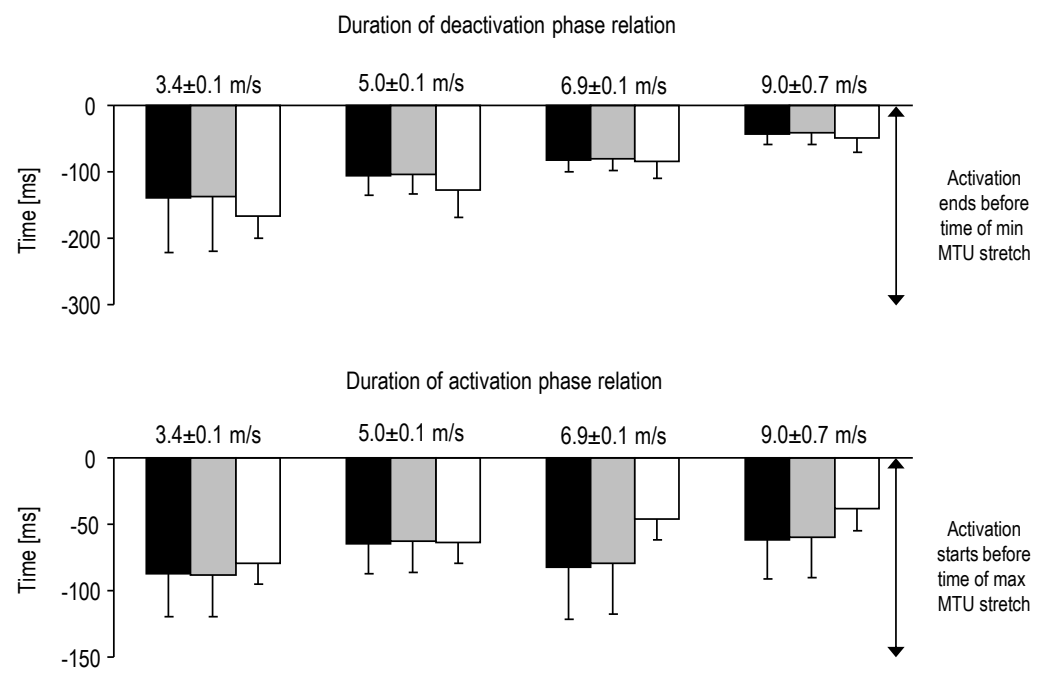

SM $\square$ ST $\square$ BFLH 


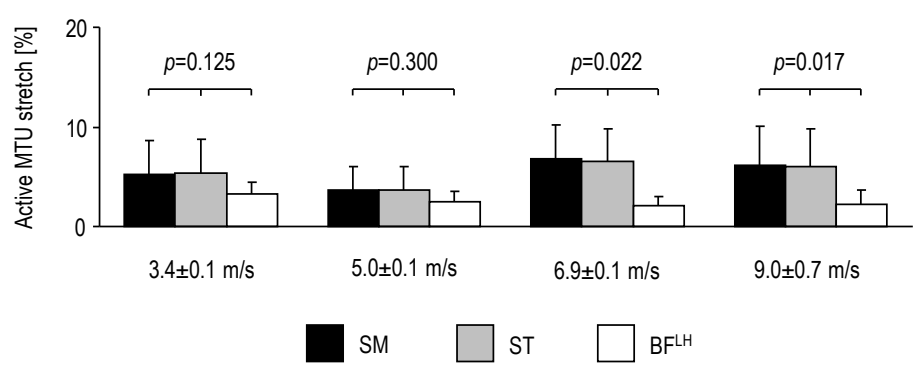

Temporal coordination between peak hamstrings MTU shortening velocity during initial swing and end of activation.
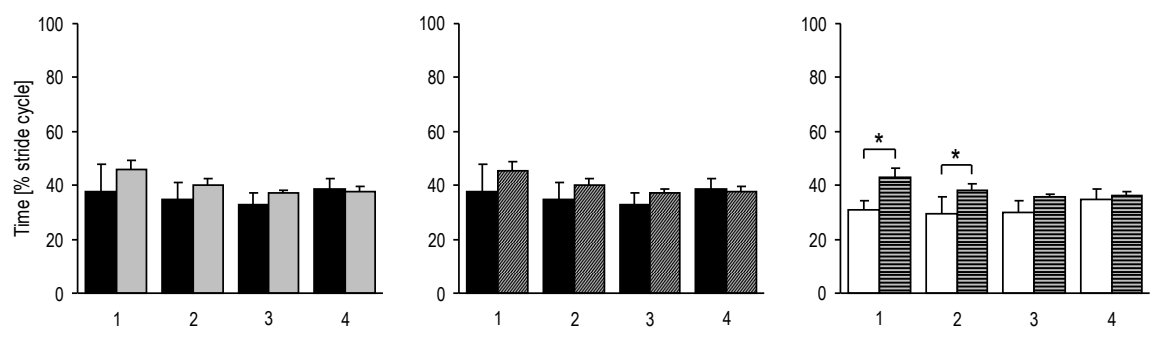

Temporal coordination between inflection point in hamstrings MTU lengthening velocity during terminal swing and start of activation
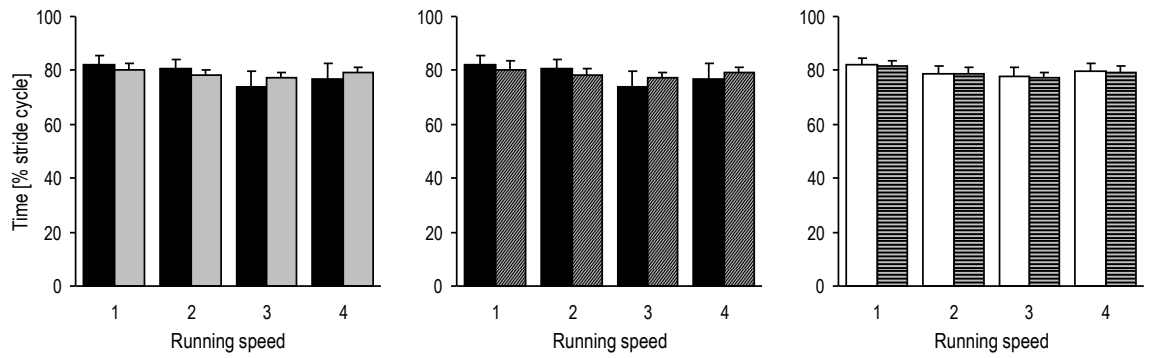

$\square$ Lateral hamstrings EMG

$\square$ sM MTU Velocity

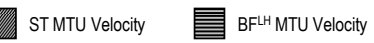

